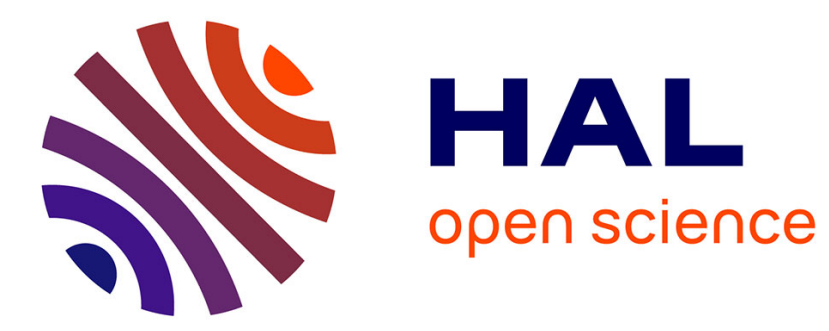

\title{
Erbium emission properties in nanostructured fibers
} Wilfried Blanc, Bernard Dussardier, Gérard Monnom, Romain Peretti, Anne-Marie Jurdyc, Bernard Jacquier, Marie Foret, Ann Roberts

\section{To cite this version:}

Wilfried Blanc, Bernard Dussardier, Gérard Monnom, Romain Peretti, Anne-Marie Jurdyc, et al.. Erbium emission properties in nanostructured fibers. Applied optics, 2009, 48 (31), pp.G119-G124. 10.1364/AO.48.00G119 . hal-00429699

\section{HAL Id: hal-00429699 \\ https://hal.science/hal-00429699}

Submitted on 5 Nov 2009

HAL is a multi-disciplinary open access archive for the deposit and dissemination of scientific research documents, whether they are published or not. The documents may come from teaching and research institutions in France or abroad, or from public or private research centers.
L'archive ouverte pluridisciplinaire HAL, est destinée au dépôt et à la diffusion de documents scientifiques de niveau recherche, publiés ou non, émanant des établissements d'enseignement et de recherche français ou étrangers, des laboratoires publics ou privés. 


\title{
Erbium emission properties in nanostructured fibers
}

\author{
Wilfried Blanc, ${ }^{1}$ Bernard Dussardier, ${ }^{1, *}$ Gérard Monnom, ${ }^{1}$ Romain Peretti, ${ }^{2}$ Anne-Marie \\ Jurdyc, ${ }^{2}$ Bernard Jacquier, ${ }^{2}$ Marie Foret ${ }^{3}$ and Ann Roberts ${ }^{4}$ \\ ${ }^{1}$ Université de Nice-Sophia Antipolis, CNRS/LPMC, Nice, France \\ ${ }^{2}$ Université Lyon 1, CNRS/LPCML, Villeurbanne, France \\ ${ }^{3}$ LCVN, Université de Montpellier 2, Montpellier, France \\ ${ }^{4}$ School of Physics, University of Melbourne, Australia \\ *Corresponding author: bernard.dussardier@unice.fr
}

A new route was recently proposed to modify some spectroscopic properties of rare-earth ions in silica-based fibers. We had shown the incorporation of erbium ions in amorphous dielectric nanoparticles, grown in fiber preforms. Here we present the achieved stabilization of nanometric erbium-doped dielectric nanoparticles within the core of silica fibers. We present the nanoparticle dimensional characterization in fiber samples. We also show the spectroscopic characterisation of erbium in preform samples with similar nanoparticle size and composition. This new route could have important potentials in improving rare-earth doped fibre amplifiers and laser sources.

OCIS codes: $060.2410,160.5690,160.6030,300.6280,350.4238,060.2320$

\section{Introduction}


Doping optical fibers with rare-earth ions has allowed the demonstration, development and marketing of numerous devices such as lasers and amplifiers. The most prominent example is the erbium-doped fiber amplifier (EDFA), developed more than twenty years ago [1]. This silicabased fiber is a key device of wavelength division multiplexing (WDM) telecommunication systems [2]. To increase the transmission capacity, one of the requirements is to broaden the amplification bandwidth. As shown earlier for various glass compositions, the linewidth of the ${ }^{4} \mathrm{I}_{13 / 22^{-}} \mathrm{I}_{15 / 2}$ stimulated emission depends on three main parameters i.e. Stark splitting, homogeneous and inhomogeneous broadenings of transitions [3]. Then, the full width at half maximum (FWHM) of the $1.5 \mu \mathrm{m}$ erbium emission is found to vary from $40 \mathrm{~nm}$ in silica to $80 \mathrm{~nm}$ in tellurite or multicomponent silicate glasses [4]. Several other applications of rare-earthdoped fibers would benefit from a modification of their spectroscopic properties. Many studies have been carried out that aimed at developing suitable silicate and non-silicate rare-earth doped glass hosts to improve their lasing and amplification properties. From a spectroscopic point of view, these glasses are more interesting than pure silica but they don't have all the advantages of the latter: low cost, reliability, connectivity, and many others.

Other approaches exist, like materials doped with semi-conductor or metallic nanoparticles, and ceramized materials. The former use the photoluminescence intensity enhancement through non-radiative energy transfer from semi-conductor or metallic nanoparticles (absorbing incident light thanks to their large cross-section) to rare-earth ions. The other interesting approach that is considered here is the ceramization of doped materials, usually made of oxides or oxy-fluorides [5]. In this case, the rare-earth or metallic luminescent ions are isolated from the matrix and located in a host that provides desired luminescent properties. Over the past several decades considerable work has been carried out on the incorporation of rare- 
earth oxide nanocrystallites into different glass hosts. Different techniques have been developed such as co-sputtering [6], pyrolysis [7], ion implantation [8], laser ablation [9] and sol-gel processes [10]. Aside from the spectroscopic advantages of these routes, the issue of optical transmission imposes that particles be of enough small size to minimize light scattering to an acceptable value. This is usually obtained for dimensions less than several tens of nanometers [11] in the case of dielectric nanoparticles, depending on their composition and on the expected application. In most cases the fiber core glass is a non-silica or a very low silica material made by the double crucible furnace melting procedure [12]. However these materials are not as reliable as compared to silica based rare earth-doped fibres.

Here we investigate the growing of dielectric (oxide) nanoparticles (DNP) in silica-based optical fibres and the modification of spectroscopic properties of erbium ions when incorporated into DNP. Through this route, we keep the advantages of the mechanical properties of silica glass and spectroscopic properties can be engineered through the choice of the DNP chemical composition. To the best of our knowledge only a few studies on nanostructured silica fibres have been dedicated to oxide DNP doped with luminescent ions [13]. To obtain DNP-doped fibers, several routes have been proposed. The one of interest here is the spontaneous phase separation mechanism [14]. In some glass systems, one observes co-existence of two liquid and/or solid phases. Silicate systems have a strong stable immiscibility when they contain divalent metals oxides, such as $\mathrm{SrO}, \mathrm{CaO}, \mathrm{FeO}, \mathrm{ZnO}$ and $\mathrm{MgO}$. As an example, if a silicate glass containing few $\mathrm{mol} \%$ of $\mathrm{CaO}$ is heated during the manufacture process, it may decompose in two phases, one silica-rich and one $\mathrm{CaO}-$ rich (present as spherical particles).

The role of calcium on the preparation of the DNP in preforms has already been discussed [15]. In the present paper, we present the preparation and characterization of fibers 
containing nanoparticles, obtained by drawing $\mathrm{Ca}$ - and Er-codoped preforms. Then, we introduce spectroscopic measurements of erbium emission obtained from preform samples containing DNP of the same composition and approximately the same size as in the fibers.

\section{Experimentals}

\section{Nanostructured preforms and fibers preparation}

Silica preforms were prepared by the MCVD process [16] ; calcium and erbium ions have been incorporated through the solution doping technique [17]. A detailed description of the technique adapted to DNP growing was reported earlier [15]. The concentration in calcium in the soaking solution was a key parameter: it was varied from 0 to $1 \mathrm{~mol} / \mathrm{l}$, whereas the concentration in erbium was the same for all samples. $\mathrm{The} \mathrm{Er}_{2} \mathrm{O}_{3}$ concentration in the sample with no calcium was estimated at about $220 \mathrm{ppm}$ mol by absorption spectroscopy. As for standard telecom fibers, germanium was added in all preforms to raise the refractive index of the core, while a small

amount of phosphorous was incorporated to ease the fabrication. Fibers were obtained by stretching preforms in a drawing tower at temperatures higher than $2000^{\circ} \mathrm{C}$ under otherwise normal conditions.

\section{Characterization of the erbium-doped dielectric nanoparticles}

Preforms and fibers were characterized through various techniques: scanning electron microscopy (SEM), transmission electron microscopy, energy dispersive X-ray spectroscopy, atomic force microscopy, quantitative phase microscopy (QPM), extended X-ray absorption fine structure. In this paper only results obtained for the first time on fibers by SEM and QPM are presented below. 
SEM pictures were realized on the exposed core section of freshly cleaved fibers. QPM measurements have been performed transversally on fiber samples to observe the DNP in the fiber core [18]. This method derives quantitative phase measurements from images captured using a bright-field microscope without phase or interference contrast optics. It is a performant and non destructive imaging technique allowing the direct observation of refractive index variations across a transversal section of objects such as optical fibers [19].

Mapping of erbium fluorescence in fiber core was investigated by a confocal microscope. The cleaved end-face of a fiber was excited at $514 \mathrm{~nm}$ with an argon laser through a microscope objective and the $\operatorname{Er}^{3+}$ green fluorescence $(\sim 540 \mathrm{~nm})$ was detected through the same microscope objective. The cleaved sample was scanned along both transverse axes under the microscope to obtain a fluorescence intensity image. The resolution of this technique is however limited by diffraction at around $1 \mu \mathrm{m}$ in size. However this is much smaller than the core typical size $(8 \mu \mathrm{m})$ and gives a qualitative distribution of erbium ions across it.

\section{$\mathrm{Er}^{3+}$ emission spectroscopy}

The series of Ca- and Er-codoped fibers studied here had high losses from scattering. As show below, the DNP average size in fiber was still to high to allow acceptable transmission. Then erbium ion distribution and surroundings were spectroscopically analysed in preform samples at room and very low temperatures $(1.5 \mathrm{~K})$. Broadband luminescence was obtained by exciting samples at $980 \mathrm{~nm}$, whereas resonant fluorescence line narrowing (RFLN) was performed at very low temperature under the excitation from a tunable external cavity laser diode around $1535 \mathrm{~nm}$, around the peak of the erbium absorption. RFLN measurements were aimed at explaining the shape of the emission band [3]. With this technique the fluorescence at the same wavelength as the excitation wavelength at low temperature indicates the zero-phonon transition 
(transition between the lowest levels of the ${ }^{4} I_{13 / 2}$ and ${ }^{4} I_{15 / 2}$ manifolds). It is then possible to identify different sites. A narrow line infrared laser at wavelength resonant with the first stark component of the electronic transition around $1.53 \mu \mathrm{m}$ was used.

Decay curves of the low-energy emission band (around $1540 \mathrm{~nm}$ ) were recorded under two different excitation wavelengths: 980 and $1536 \mathrm{~nm}$. The sample was a >4-mm long parallelepiped extracted from a preform, containing a cylindrical Er-doped core surrounded by pure silica. The pump beam was modulated in time with a 1-ms "square shape". It was directed into the core along its longitudinal axis. The emitted light was collected transversally from two different points relative to the coupled pump: 1) close to the excitation point and 2) at $4 \mathrm{~mm}$ far from this point. The fluorescence decay signals were collected with a infrared sensitive photomultiplier Hamamatsu R 5509 (response time of the system: $100 \mu \mathrm{s}$ ) and displayed on an oscilloscope.

\section{Results and discussion}

In Figure 1 are shown images obtained by the Quantitative Phase Microscopy technique. The core of the fiber corresponds to the central darker part. Calcium concentration was varied from 0 to $1 \mathrm{~mol} / \mathrm{l}$ (from bottom to top, in Figure 1). We clearly observe some dark spots in the core which are ascribed to nanoparticles. As it was reported in preforms, DNP are observed only for Ca concentration of $0.1 \mathrm{~mol} / \mathrm{l}$ or higher [20]. The absence of DNP for low concentration can be explained by the fact that, according to the $\mathrm{SiO}_{2}-\mathrm{CaO}$ binary phase diagram, the immiscibility gap occurs for a $\mathrm{CaO}$ concentration between 2 and $26 \mathrm{~mol} \%$. The DNP average size can not be deduced from this technique due to the diffraction limit. However, we can clearly observe that DNP are always almost spherical and the volumic fraction increases with calcium concentration. In the following, we focus our attention on samples doped with a solution containing $0.1 \mathrm{~mol} / 1$ of 
calcium. SEM pictures from such a fiber is shown on Figure 2. The fiber core corresponds to the light gray disk. Its diameter is $\sim 8 \mu \mathrm{m}$. The central part of the core is almost dark due to the evaporation of germanium and calcium elements; this is a common artifact of the MCVD technique. The inset of Figure 2 shows typical spherical DNP. The DNP mean size was determined by averaging DNP diameter across the whole core sections for several SEM pictures. It was found around $100 \mathrm{~nm}$ and no particles bigger than $200 \mathrm{~nm}$ were observed., whereas in preform samples, the average size was $250 \mathrm{~nm}$. Therefore although the drawing of the preform into fiber reduced the core diameter by a factor $\sim 70$, DNP average diameter stayed within the $100 \mathrm{~nm}$ range. This shows that DNP of this particular composition remain stable in the material although it was submitted to a strong deformation at high temperature. Other phase separating agents with a high immiscibility gap may give a better DNP size stablility. The phenomenon still needs further investigations, using molecular dynamics simulations for instance.

Mapping of the $\mathrm{Er}^{3+}$ emission intensity by confocal microscopy is reported on Figure 3. Intensity is not homogeneously distributed in the core. A maximum clearly appears in a region of less than $1 \mu \mathrm{m}$ in diameter (due to diffraction limit). This result indicates that erbium ions are located inside or very close to the DNP as it was observed in preforms through EDX analyses [20]. Note that no erbium fluorescence is detected outside the DNP. This result was expected due to the low solubility of silica (or even germano-silicate) for rare-earth ions, whereas strongly modified and amorphous silicates, such as in the DNP, have a high solubility for these ions.

At room temperature, it was observed that erbium emission depends on calcium concentration. For the lowest concentration $(0.01 \mathrm{~mol} / \mathrm{l})$, when no DNP are observed, erbium emission is similar to that from a standard silica erbium-doped preform when no calcium is added to the core composition (Figure 4). However, when calcium concentration is $0.1 \mathrm{~mol} / \mathrm{l}$, 
erbium emission spectrum is broadened [15]. At very low temperature, the same was observed (not shown here). It is assumed that the change of local order around the erbium ions embedded into the calcium rich phase is responsible of the observed broadening. This luminescent broadening is the signature of a sensible modification of the close environment of rare earth ions in DNP-doped fibers, compared to standard silica fibers. To investigate this, RFLN spectroscopy was performed. Spectra obtained for two excitation wavelengths (1539.6 and $1534.6 \mathrm{~nm})$ are presented on Figure 5. At low energy excitation (1539.6 nm on Figure 5), one main fluorescent peak is observed, resonant with the excitation wavelength. A second emission band exists at $1545 \mathrm{~nm}$ too, and is present for any excitation wavelength. Its origin is still unclear and is not discussed in this paper. At higher energy excitation (1534.6 nm on Figure 5), we observed unusual spectra because, additionally to the resonant fluorescence peak, a high and broad emission band appears at lower energy $\left(\sim 6500 \mathrm{~cm}^{-1}\right)$. Such a band has never been observed in this kind of samples. However, the same was reported with neodymium doping and interpreted as the result of energy transfer [21].

To confirm and analyze the existence of an energy transfer in our sample, we study the results from fluorescence lifetime measurements. It was observed that when the light is collected far from the excitation point, the measured lifetime is increased compared to that measured on the decay curve corresponding to collection of light at the excitation point (Figure 6). This was observed for two different excitation wavelengths. Note that the lifetime measured at the excitation point is similar to that from a standard erbium-doped fiber. We assign this behavior of the 1540-nm emission band to a self absorption phenomenon within erbium ions. Self-absorption is a radiative transfer from a donor to an acceptor of the same nature. We will show in the following that the hypothesis of transfer shown in RFLN can be explained by self absorption. At 
low temperature, self absorption by similar Stark level cannot induce the apparition of additional band in the RFLN spectrum. This is why self absorption occurs between two different $\mathrm{Er}^{3+}$ ions having energy-coincident Stark levels, namely the lowest Stark level of the donor $\mathrm{Er}^{3+}$ ions, and the second level of acceptor $\mathrm{Er}^{3+}$. The energetic structure of those two $\mathrm{Er}^{3+}$ ions sites are so different that it can be concluded that their environments are different. This prooves that radiative transfer phenomenon occurs between to different classes of sites. This hypothesis is reinforced by the full sites distribution of erbium in this material shown in ref [22], which is the sum of two Gaussians.

Usually, radiative energy transfer is observed in heavily doped materials [23,24,25]. Although the concentration is low in our samples, a self absorption effect is observed when the emitted light comes across a highly absorbant and/or many absorbing centers on its free path. Two factors can simultaneously cause this self absorption effect. On one hand, scattering of light is enhanced due to the presence of DNP, hence increasing the mean free path of light in the core and the self absorption probability. On the other hand, if erbium ions are located into (or close to) the DNP, absorption cross-section could be modified because DNP are chemically very different compared to the silica host..

\section{Conclusion}

In this paper, we have demonstrated that it is possible to obtain dielectric nanoparticles doped fibers directly through the MCVD process. These DNP are used to embed erbium ions. Isolated from silica glass, rare-earth ions spectroscopic properties are then modified by the DNP chemical compositions. We have then shown, with Er-DNP-doped preforms, the existence of two types of sites for erbium ions and evidenced a radiative energy transfer between them. Also, an increase of the erbium emission bandwidth is measured at room temperature. These observations open 
interesting perspectives in various fields of application for rare-earth-doped optical fibers. Particularly, the sensible broadening of the erbium luminescence around $1.55 \mu \mathrm{m}$ is very interesting for optical telecommunications or short pulsed laser sources, where intrinsically broad and flattened gain must be implemented in reliable silica-base optical fibers. Generally speaking, this new generation of fibers would allow new applications for silica-based amplifying optical fibers.

\section{Acknowledgements}

The authors acknowledge support from CNRS and the Ministère des Affaires Etrangères (France) (P2R project \# P2RI 04-11), and from the Australian Research Council. The authors also thank Michèle Ude and Stanislaw Trzésien for samples preparation, and Luan Nguyen (CNRS-CRHEA, Valbonne) for SEM images. 


\section{References}

1 R.J. Mears, L. Reekie, I.M. Jauncey, D.N. Payne, "Low noise erbium-doped fibre amplifier operating at $1.54 \mu \mathrm{m} ”$, Electron. Lett. 23, 1026-1068 (1987).

2 E. Desurvire, D. Bayart, B. Dethieux and S. Bigo, Erbium-Doped fiber Amplifier, Device and System Developments, Wiley Interscience, New York, 2002.

3 L. Bigot, A.-M. Jurdyc, B. Jacquier, L. Gasca, D. Bayart, "Resonant fluorescence line narrowing measurements in erbium-doped glasses for optical amplifiers”, Phys. Rev. B. 66, 214204 (2002).

4 J. Yang et al.,'Effect of $\mathrm{Bi}_{2} \mathrm{O}_{3}$ on the spectroscopic properties of erbium-doped bismuth silicate glasses", J. Opt. Soc. Am. B, 20, 810 (2003).

5 Y. Wang, J. Ohwaki, "New transparent vitroceramics codoped with $\mathrm{Er}^{3+}$ and $\mathrm{Yb}^{3+}$ for efficient frequency upconversion”, Appl. Phys. Lett. 63, 3268-3270 (1993).

6 M. Fujii, M. Yoshida, S. Hayashi, K. Yamamoto, «Photoluminescence from SiO2 films containing Si nanocrystals and Er: effects of nanocrystalline size on the photoluminescence efficiency of $\mathrm{Er}^{3+} \gg$, J. Appl. Phys. 84, 4525-4531 (1998).

7 J. St. John, J. L. Coffer, Y. Chen, and R. F. Pinizzotto, "Synthesis and characterization of discrete luminescent erbiumdoped silicon nanocrystals”, J. Am. Chem. Soc. 121, 1888-1892 (1998).

8 C. E. Chryssou, A. J. Kenyon, T. S. Iwayama, C. W. Pitt, and D. E. Hole, "Evidence of energy coupling between Si nanocrystals and $\mathrm{Er}^{3+}$ in ion-implanted silica thin films », Appl. Phys. Lett. 75, 2011-3013 (1999). 
9 W.T. Nichols, John W. Keto, D.E. Henneke, J. R. Brock, G. Malyavanatham, M. F. Becker, and H.D. Glicksman, "Large-scale production of nanocrystals by laser ablation of microparticles in a flowing aerosol", Appl. Phys. Lett. 78, 1128-1130 (2001).

10 E.M. Yeatman, M.M. Ahmad, O. McCarthy, A. Martucci, M. Guglielmi, "Sol-Gel Fabrication of Rare-Earth Doped Photonic Components”, J. Sol-Gel Sci. Tech. 19, 231-236 (2000).

11 P.A Tick, "Are low-loss glass ceramic optical waveguide possible?" Opt. Lett. 23, 1904 (1998).

12 B. N. Samson, P. A. Tick, N. F. Borrelli, "Efficient neodymium-doped glass-ceramic fiber laser and amplifier", Opt. Lett. 26, 145-147 (2001).

13 S. Yoo, U.-C. Paek, W.-T. Han, «Optical properties of the optical fiber containing $\mathrm{Co}^{2+}$ doped $\mathrm{ZnO}-\mathrm{Al}_{2} \mathrm{O}_{3}-\mathrm{SiO}_{2}$ glass-ceramics », J. Non-Cryst. Solids 303, 291-295 (2002).

14 J. Zarzycki, Glasses and the vitreous state, edited by Cahn R.W., Davis E.A. and Ward I.M., Cambridge University Press, Cambridge, 1991.

15 W. Blanc, B. Dussardier, M.C. Paul, "Er-doped oxide nanoparticles in silica-based optical fibers", Glass Technol.: Eur. J. Glass Sci. Technol. A, 50, 79 (2009).

16 S.R. Nagel, J.B. McChesney, K.L. Walker, Modified Chemical Vapor Deposition, in: T. Li (Ed.), Optical Fiber Telecommunications: Fiber Fabrication, Vol.1, Academic, Orlando, 1985.

17 J.E Townsend, S.B. Poole, D.N. Payne, "Solution-doping technique for fabrication of rareearth-doped optical fibers". "Solution-doping technique for fabrication of rare-earth-doped optical fibers", Electron. Lett. 23, 329 (1987).

18 A. Barty et al., "Quantitative optical phase microscopy", Opt. Lett. 23, 817 (1998). 
19 A. Roberts, E. Ampem-Lassen, A. Barty, K. A. Nugent, G. W. Baxter, N. M. Dragomir, S. T. Huntington, « Refractive-index profiling of optical fibers with axial symmetry by use of quantitative phase microscopy », Opt. Lett. 27, 2061-2063 (2002).

20 F. d'Acapito, C. Maurizio, M. C. Paul, Th. S. Lee, W. Blanc, B. Dussardier, "Role of CaO addition in the local order around erbium in $\mathrm{SiO}_{2}-\mathrm{GeO}_{2}-\mathrm{P}_{2} \mathrm{O}_{5}$ fiber preforms", Mat. Sc. Eng. B. 146, 167 (2008).

21 Optical Energy Transfer in Insulators ,W.M. Yen, M.C. Downer, G.P. Morgan Chap 3 of W.M. Yen, M.C. Downer, G.P. Morgan, B.Henderson, K.P. O'donnel, D.D. Dlott, C.Klingshirn, and P.C. Taylor. in Laser Spectroscopy of Solids II, volume 65 of Topics in Applied Physics. Springer-Verlag, 1989.

22 R. Peretti, « Saturation spectrale de gain dans les amplificateurs à fibres dopées erbium : largeur homogène et inhomogène et approche des nano matériaux », $\mathrm{PhD}$ Thesis, Universté Claude Bernard Lyon1 (2008)

23 A. Bensalah, M. Ito, Y. Guyot, C. Goutaudier, A. Jouini, A. Brenier, H. Sato, T. Fukuda, G. Boulon, "Spectroscopic properties and quenching processes of $\mathrm{Yb}^{3+}$ in fluoride single crystals for laser applications ", J. Lum. 122, 444-446 (2007).

24 . A. Stoita, S. Guy, B. Jacquier, "Measurement of the fraction of reabsorbed light in an $\mathrm{Er}^{3+}$-doped glass", Appl. Phys. B: Lasers and Optics 87, 445-449 (2007).

25 S. Guy, « Modelization of lifetime measurement in the presence of radiation trapping in solid-state materials », Phys. Rev. B. 73,144101 (2006). 


\section{Figure Captions}

Figure1: Quantitative Phase Microscopy measurement on Ca-doped fibers. The bright region is the $125-\mu \mathrm{m}$ diameter cladding, the core is the dark central region (diameter $\sim 8 \mu \mathrm{m}$ ). The calcium concentration in the doping solution is (from top to bottom) $1,0.1,0.01$ and $0 \mathrm{~mol} / \mathrm{l}$, respectively

Figure 2 : SEM pictures of fibers doped with $0.1 \mathrm{~mol} / 1$ of calcium. Black regions correspond to pure silica, whereas grey and white regions are chemically contrasted. The light gray ring corresponds to the Ge-doped core, of diameter $8 \mu \mathrm{m}$. Inset: zoom on typical DNP.

Figure 3 : Mapping of $\mathrm{Er}^{3+}$ emission intensity in a Ca-doped fiber $(0.1 \mathrm{~mol} / \mathrm{l})$ under a confocal microscope. Intensity increases from blue to red. The dashed line delimits the fiber core. Excitation : $514 \mathrm{~nm}$, detection: $540 \mathrm{~nm}$.

Figure 4: Room temperature erbium emission spectra in standard preform (dashed line) and DNP-doped preform with 0.01 and $0.1 \mathrm{~mol} / 1$ of calcium (grey and black line, respectively). . Excitation wavelength: $980 \mathrm{~nm}$.

Figure 5 : Resonant fluorescence of erbium emission for two excitation wavelengths.

Figure 6: Fluorescence decay at $1.5 \mathrm{~K}$ from a Ca-doped preform sample at $1540 \mathrm{~nm}$, measured close to the excitation point (dark solid line) and at $4 \mathrm{~mm}$ away from it (gray line). Excitation: $980 \mathrm{~nm}$ (top) and $1536 \mathrm{~nm}$ (bottom). Pump is modulated with $1 \mathrm{~ms}-$ long pulses. 
Figure 1

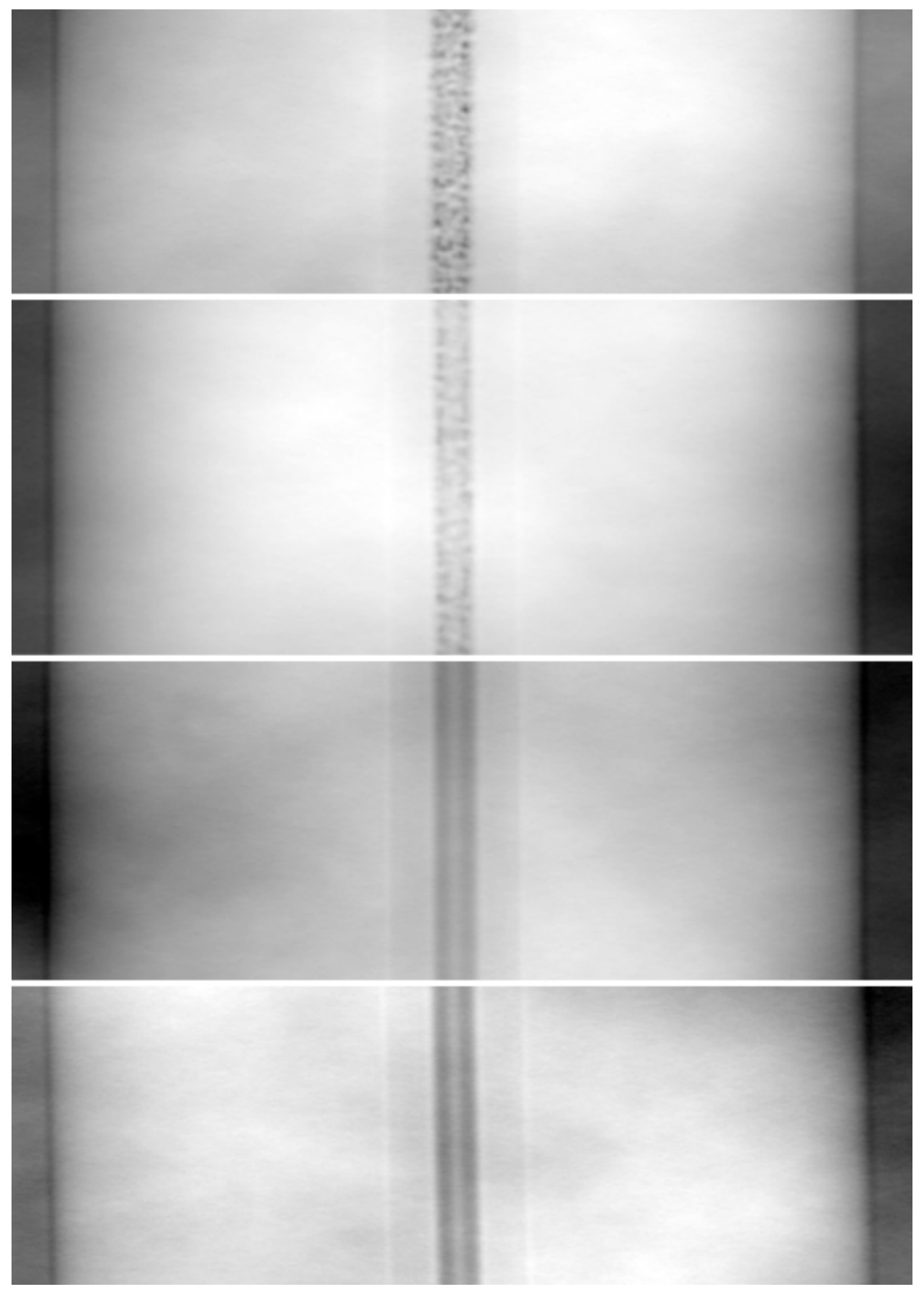


FIGURE 2:

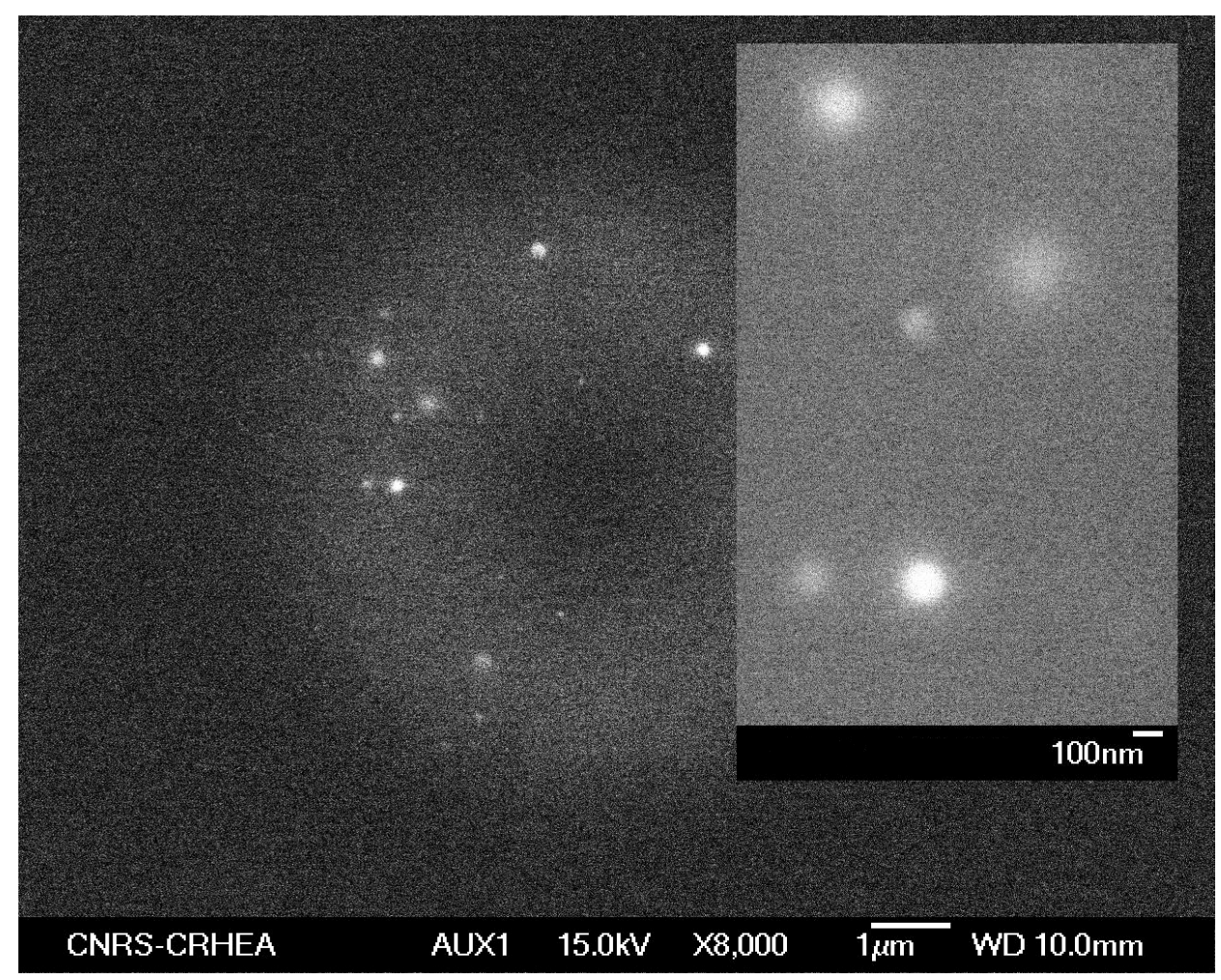


Figure 3

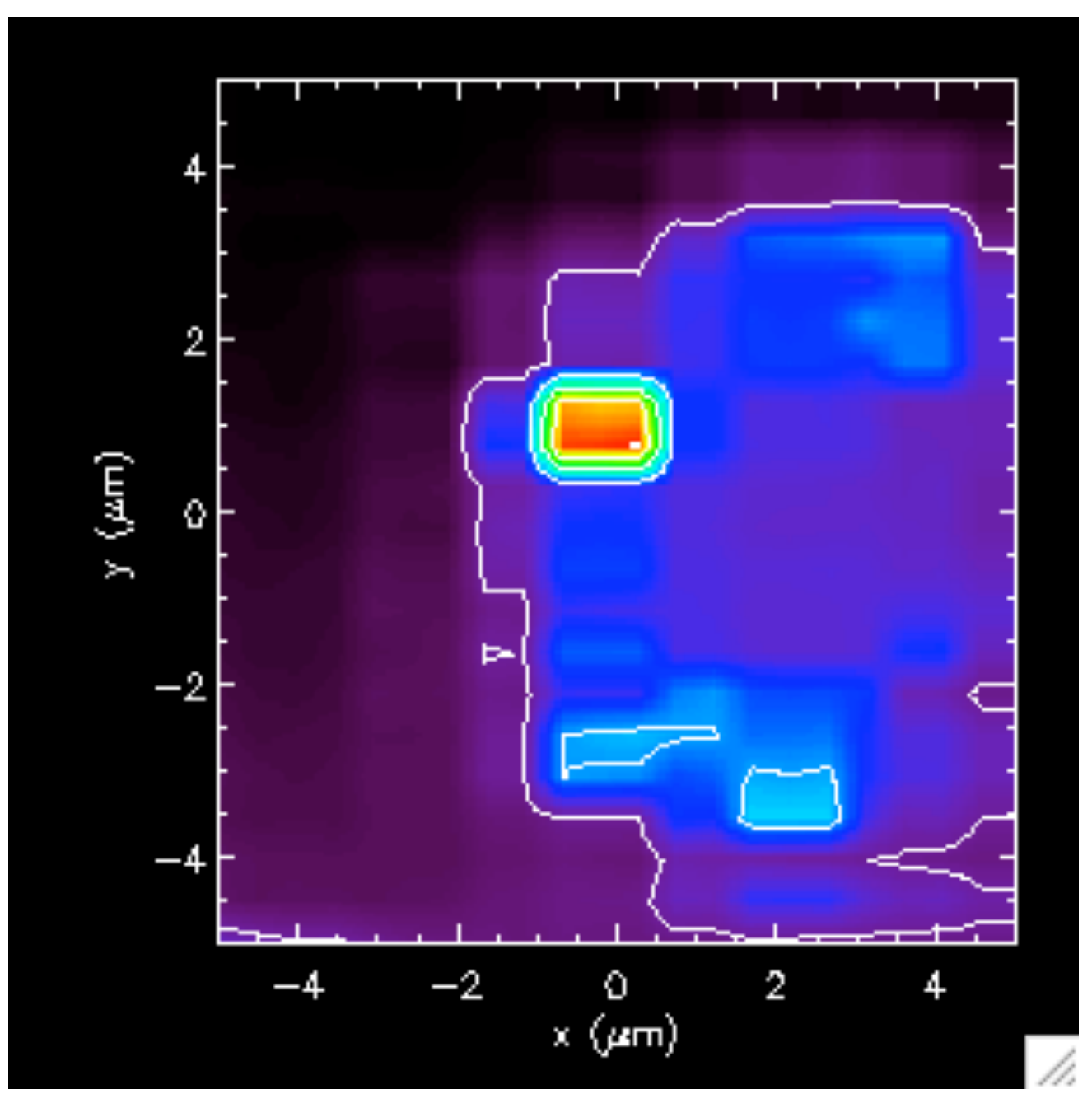


Figure 4

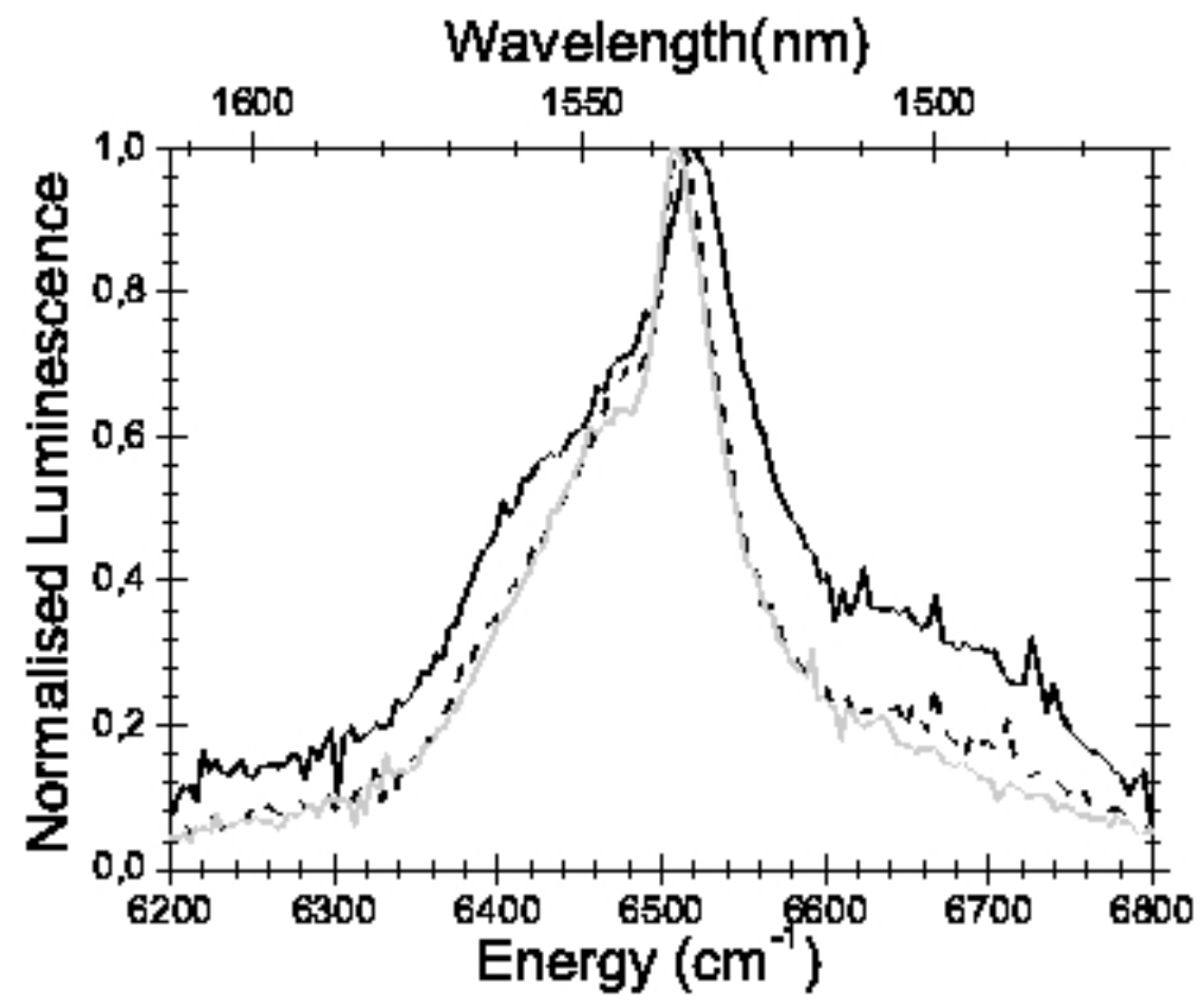


Figure 5

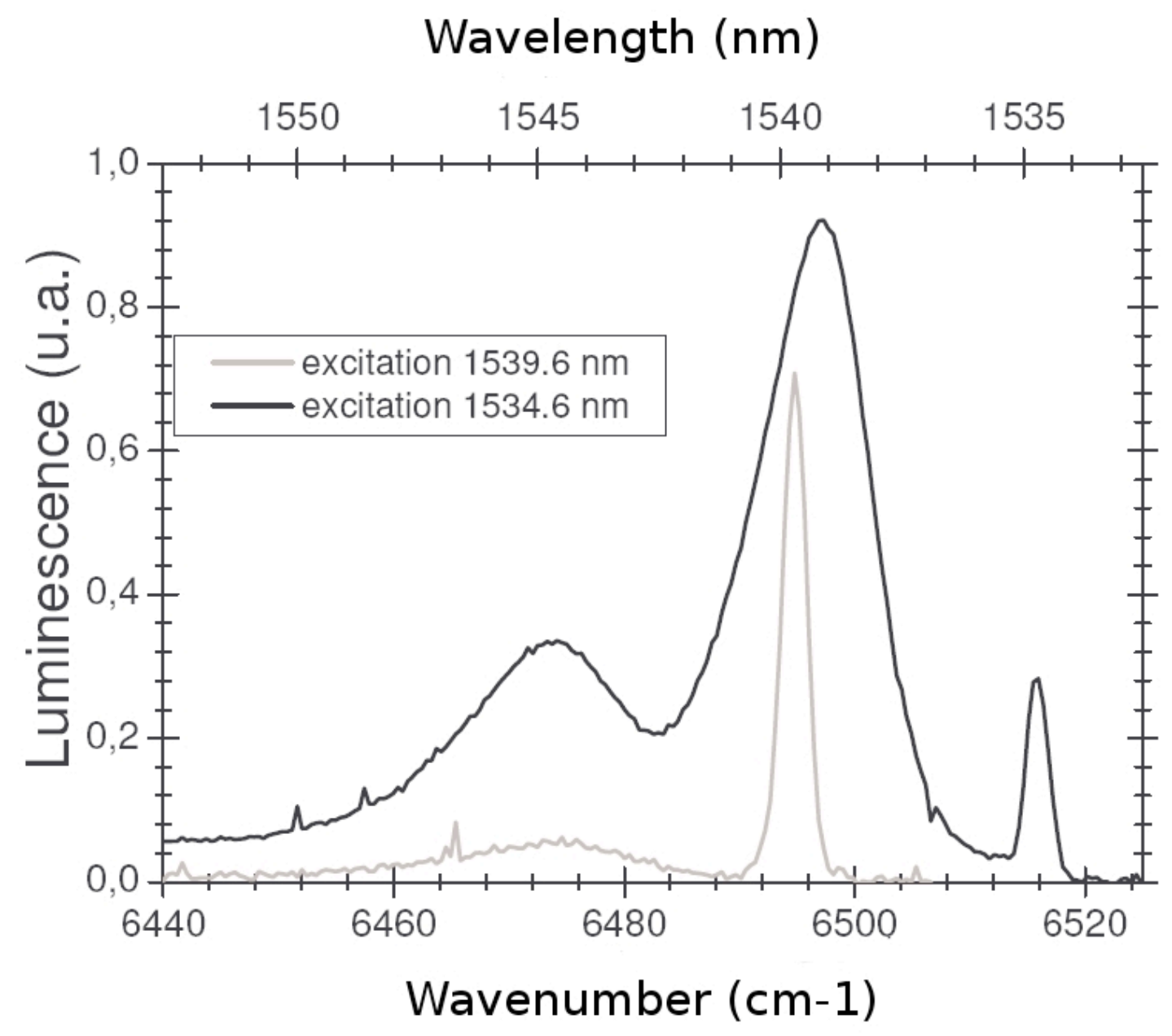


Figure 6:

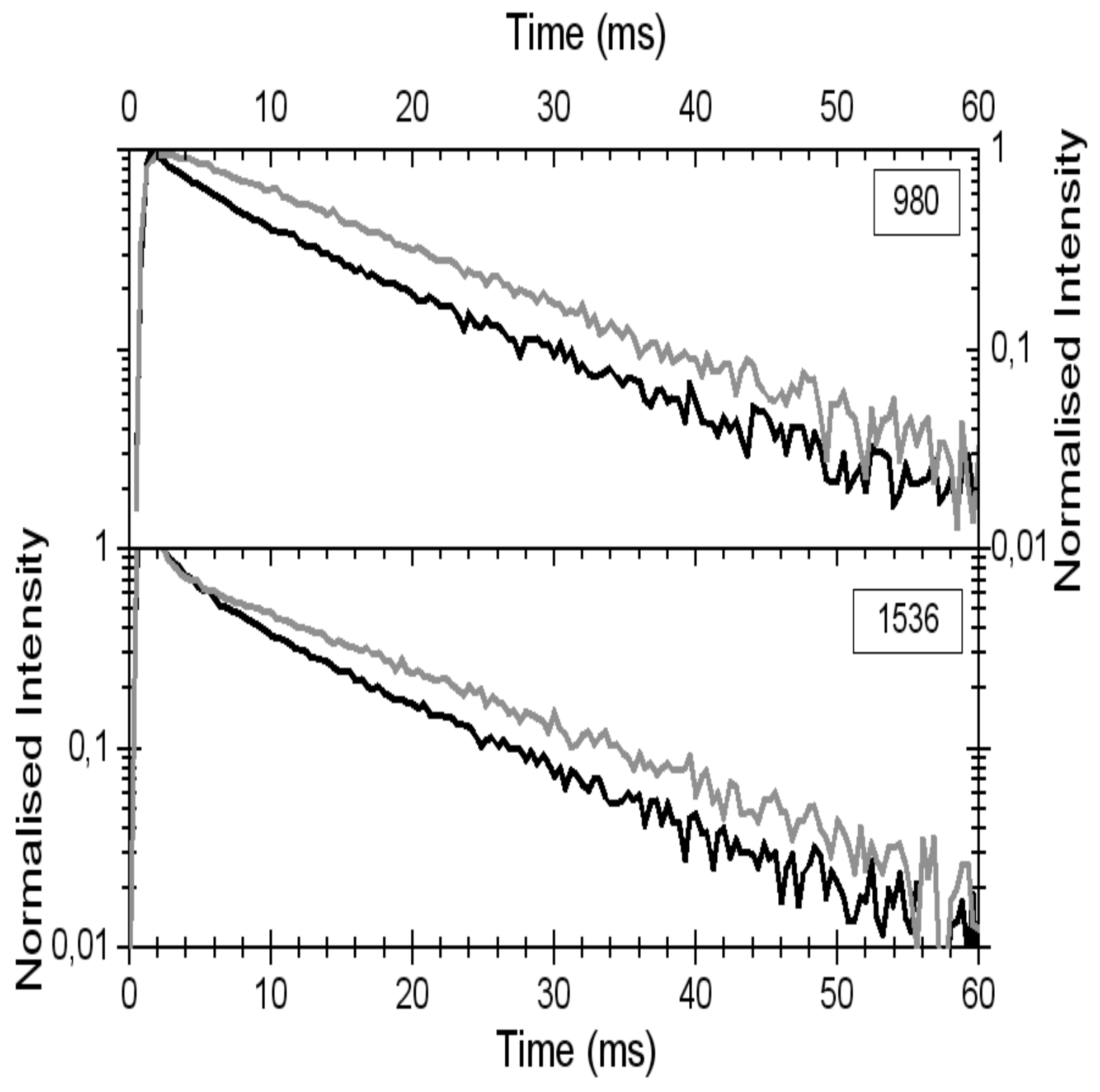

